Received: 29 March 2017

Accepted: 17 October 2017

Published online: 31 October 2017

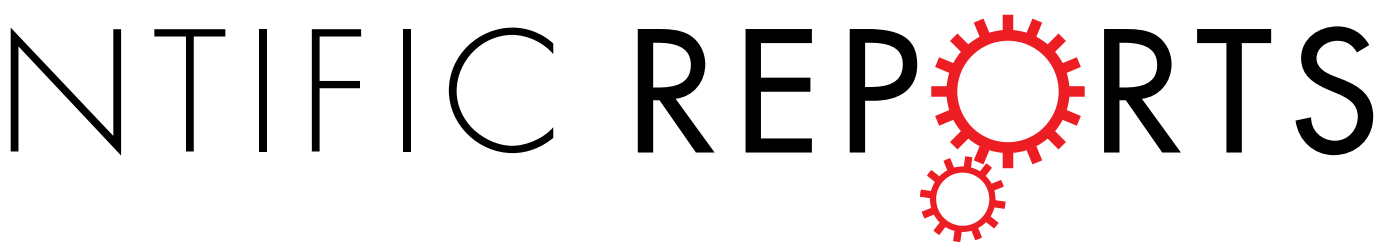

\title{
Knockout of OsNramp5 using the CRISPR/Cas9 system produces low Cd-accumulating indica rice without compromising yield
}

\begin{abstract}
Li Tang ${ }^{1,2}$, Bigang Mao ${ }^{2}$, Yaokui Li ${ }^{2}$, Oiming Lv' ${ }^{2}$ LiPing Zhang ${ }^{3}$, Caiyan Chen ${ }^{3}$, Hanjie $\mathrm{He}^{2,4}$, Weiping Wang ${ }^{2}$, Xiongfeng Zeng ${ }^{1}$, Ye Shao ${ }^{2}$, Yinlin $\mathrm{Pan}^{2}$, Yuanyi $\mathrm{Hu}^{2}$, Yan Peng ${ }^{2}$, Xiqin Fu' Hongqing $\mathrm{Li}^{5}$, Shitou $\mathrm{Xia}^{1}$ \& Bingran $\mathrm{Zhao}^{2}$
\end{abstract}

Rice grain with excessive cadmium (Cd) is a major source of dietary Cd intake and a serious threat to health for people who consume rice as a staple food. The development of elite rice cultivars with consistently low $\mathrm{Cd}$ content is challenging for conventional breeding approaches, and new strategies urgently need to be developed. Here, we report the development of new indica rice lines with low $\mathrm{Cd}$ accumulation and no transgenes by knocking out the metal transporter gene OsNramp 5 using CRISPR/ Cas9 system. Hydroponic culture showed that $\mathrm{Cd}$ concentrations in shoots and roots of osnramp5 mutants were dramatically decreased, resulting in rescue of impaired growth in high Cd condition. Cd-contaminated paddy field trials demonstrated that $\mathrm{Cd}$ concentration in osnramp5 grains was consistently less than $0.05 \mathrm{mg} / \mathrm{kg}$, in contrast to high Cd concentrations from $0.33 \mathrm{mg} / \mathrm{kg}$ to $2.90 \mathrm{mg} /$ $\mathrm{kg}$ in grains of Huazhan (the wild-type indica rice). In particular, the plant yield was not significantly affected in osnramp 5 mutants. Furthermore, we developed promising hybrid rice lines with extremely low Cd content in grains. Our work supplies a practical approach to developing Cd pollution-safe indica rice cultivars that minimizes $\mathrm{Cd}$ contamination risk in grains.

Cadmium (Cd) is a highly toxic heavy metal for most living organisms ${ }^{1}$. The biological half-life of Cd in the human body is estimated to be nearly 30 years $^{2}$. Persistent intake of Cd can lead to chronic kidney toxicity, 'itai-itai disease', cancer and other health problems ${ }^{3}$. Rice is an important staple food for more than half of the world's population ${ }^{4}$, and about $90 \%$ of the world's rice is produced in Asia ${ }^{5}$. A recent survey showed that the mean concentration of $\mathrm{Cd}$ in rice grain samples from Asia was higher than in samples from Europe, the Middle East, and North America ${ }^{6}$. In South and Southeast Asia, indica rice is the main type produced and consumed ${ }^{2}$. Cd contamination of rice grains in these areas has been reported from China ${ }^{5}$, India ${ }^{7,8}$, Thailand ${ }^{9}$, Indonesia ${ }^{6,10}$, Bangladesh $^{8}$, and Sri Lanka ${ }^{8}$. In general, Cd content in shoots and grains was higher in standard indica rice cultivars than in japonica rice cultivars ${ }^{11-14}$. Therefore, controlling $\mathrm{Cd}$ accumulation in indica rice grains is important for food safety and the health of people who consume rice as a staple of their diet.

Rice grains acquire Cd from contaminated paddy fields. Treatments such as soil removal and replacement, chemical washing, or phytoremediation can repair contaminated soil, but all of these methods are expensive and/ or time-consuming ${ }^{15,16}$. Some measures such as lime and charcoal application, or field flooding for 3 weeks before and after rice heading, can limit the mobility and bioavailability of Cd. However, these methods may also reduce grain yield and are not long-term solutions, because $\mathrm{Cd}$ can be remobilized with changes in soil conditions ${ }^{17,18}$.

${ }^{1}$ Hunan Provincial Key Laboratory of Phytohormones and Growth Development, College of Bioscience and Biotechnology, Hunan Agricultural University, Changsha, 410128, China. ${ }^{2}$ State Key Laboratory of Hybrid Rice, Hunan Hybrid Rice Research Center, Changsha, 410125, China. ${ }^{3}$ Key Laboratory of Agro-Ecological Processes in Subtropical Region, Institute of Subtropical Agriculture, Chinese Academy of Sciences, Changsha, 410125, China. ${ }^{4}$ Hunan Provincial Key Laboratory of Forestry Biotechnology, Central South University of Forestry and Technology, Changsha, 410004, China. ${ }^{5}$ Guangdong Provincial Key Lab of Biotechnology for Plant Development, South China Normal University, Guangzhou, 510631, China. Correspondence and requests for materials should be addressed to H.L. (email: hqli@scnu.edu.cn) or S.X. (email: xstone0505@hunau.net) or B.Z. (email: brzhaorice@163.com) 
Selection and breeding of low-Cd accumulation rice cultivars is an economical strategy, and would allow rice production in Cd-polluted soils ${ }^{5,11,14}$.

Understanding the physiological processes and molecular mechanisms of Cd uptake and transport within rice is essential for low-Cd rice breeding. Cd is uptaken by roots from the soil, transported into shoots through xylem flow, and accumulated in leaves and stems. During the reproductive growth phase, most Cd transported by xylem is transferred to phloem in the nodes and is then preferentially transported into upper nodes and grains rather than into leaf blades. These results are based on visualization of $\mathrm{Cd}$ in real time by a positron-emitting tracer imaging system (PETIS) ${ }^{19}$. Furthermore, Cd stored in leaf blades is remobilized through phloem and transported into grains after redirection in nodes during the ripening stage ${ }^{2,15}$. Many Cd transporters have been identified and characterized, including: OsIRT1, OsIRT2, and two members of the natural resistance associated macrophage proteins (NRAMP) family, OsNramp5 and OsNramp1, which mediate the root uptake of $\mathrm{Cd}^{20-23}$; OsHMA3, which sequesters $\mathrm{Cd}$ into vacuoles of root cells ${ }^{24,25}$; OsHMA2, which facilitates xylem loading of $\mathrm{Cd}^{26,27}$; and OsLCT1, which plays a role in transferring Cd from xylem to phloem in nodes and transporting Cd by phloem ${ }^{28}$. Modifying these transporter genes may reduce Cd content in rice. Among them, mutating OsNramp 5 causes the largest reduction in Cd content. In a previous study, osnramp5 mutants with a background of the japonica cultivar Koshihikari were isolated from an ion-beam irradiated population. When grown in Cd-contaminated paddy fields, these mutants accumulated only a slight amount of Cd in grains, ranging from $0.01-0.03 \mathrm{mg} / \mathrm{kg}$, less than $3 \%$ of the amount in grains of wild type plants. Notably, osnramp 5 mutants did not show any significant defects of important agronomical traits such as growth, yield, or taste, although the mutants showed a remarkable reduction of manganese (Mn) content ${ }^{21}$. The T-DNA insertion mutant of OsNramp5 (with a background of japonica cultivar Zhonghua 11) also showed huge reductions in $\mathrm{Cd}$ and $\mathrm{Mn}$ accumulation, but the grain yield of this mutant was only $11 \%$ of the wild-type plants ${ }^{20}$. Indica rice tends to accumulate more Cd than japonica cultivars, but the effects of OsNramp5 mutation on accumulation of $\mathrm{Cd}$ and other relevant metals, and on major agronomic traits have not yet been clarified in indica rice.

Hybrid rice has a 10-20\% yield advantage over conventional rice and has been developed in more than 40 countries worldwide ${ }^{29,30}$. Indica hybrids dominate hybrid rice production, especially in southern China. However, a considerable proportion of rice grains contaminated with excess Cd have been found in southern China ${ }^{5,31}$. Thus, genetic improvements in hybrid rice directed at low-Cd accumulation in grains have become a top priority for hybrid rice breeders. So far, there is no Cd pollution-safe rice germplasm in which grains consistently accumulate lower Cd than the national food safety standard of $0.2 \mathrm{mg} / \mathrm{kg}$ when grown in high Cd-contaminated paddy fields in China. In 2016, researchers grew 617 indica hybrid varieties from the middle and lower Yangtze River Valley in China and 68 inbred rice cultivars from around the world in paddy fields with soil Cd concentration between 1.80 and $2.80 \mathrm{mg} / \mathrm{kg}$. They found that grain Cd levels ranged from 0.67 to $7.83 \mathrm{mg} / \mathrm{kg}$, much higher than the national standard ${ }^{32}$. The deficiency of Cd pollution-safe germplasm has limited the breeding of low-Cd rice cultivars and hybrid rice combinations. Thus, new technologies to minimize the $\mathrm{Cd}$ content in rice grains are urgently required to reduce the risk of Cd contamination.

In recent years, genome editing technologies have been successfully used to genetically modify plants ${ }^{33-38}$. Among them, CRISPR/Cas9 (Clustered Regularly Interspaced Short Palindromic Repeats/CRISPR-associated Cas9) has revolutionized genome editing and is widely used because of its simplicity, efficiency, and versatility. However, there are only a few reports to date in which the CRISPR/Cas9 system has been successfully used for rice genetic improvement ${ }^{30,39-44}$.

In this report, we obtained osnramp5 mutants with backgrounds of Huazhan (HZ) and Longke638S (638S), both of which are extensively used indica parental lines in the current two-line hybrid rice breeding. The transgene-free homozygous mutants were efficiently isolated in the $\mathrm{T}_{1}$ generation. Notably, the mutants had extremely low-Cd content in grains and did not show stunted growth or reduced yield when grown in highly Cd-contaminated paddy fields. Furthermore, the Cd concentration in grains of Long-liang-you-hua-zhan (LLYHZ or $638 \mathrm{~S} / \mathrm{HZ}$ ), a widely cultivated super-hybrid rice in China, was rapidly and considerably reduced by crossing the $\mathrm{HZ}$ mutant and $638 \mathrm{~S}$ mutant.

\section{Results}

Site-specific mutagenesis of OsNramp5 induced by CRISPR/Cas9 system. We chose to target exon IX of OsNramp5 for CRISPR/Cas9-based mutagenesis, as mutations in this exon have been shown to result in low $\mathrm{Cd}$ concentration of grains in the japonica Koshihikari background ${ }^{21}$. We designed two sequence-specific single guide RNA (sgRNA) target sites, OsNramp5-PS1 and OsNramp5-PS2, which are 119bp apart in the OsNramp5 sequence (Fig. 1a). Then they were ligated into two sgRNA expression cassettes of a Cas 9 binary vector ${ }^{45}$, driven by OsU6 and OsU3 promoters, respectively. The vector was introduced into HZ and 638S by Agrobacteriummediated transformation. Using site-specific PCR and Sanger sequencing, a total of $14 \mathrm{HZ}$ mutants were recovered from $17 \mathrm{~T}_{0}$ transgenic $\mathrm{HZ}$ plants (82.4\%) and $8638 \mathrm{~S}$ mutants were recovered from $10 \mathrm{~T}_{0}$ transgenic $638 \mathrm{~S}$ plants $(80.0 \%)$. Mutation efficiency of individual target sites was varied and depended on different target sites and backgrounds, ranging from $70.0 \%$ to $82.4 \%$ (Table 1 ). The majority of mutations were short insertions and deletions (indels), except for one deletion of a $225 \mathrm{bp}$ DNA fragment spanning the two target sites. Every 4 th base upstream of the protospacer adjacent motif (PAM) was mutated, and aligned perfectly with the expected Cas 9 cleavage site, which is 3 base pairs upstream of the PAM sequence (Fig. 1b).

The genotypes of the $\mathrm{T}_{0}$ mutants were analysed in detail by sequencing the PCR products of DNA extracted from at least 5 leaves from different tillers during grain maturation. The genotypes of the mutants could be classified into 4 types: 1) homozygotes with both alleles containing the same mutations, including lines HZ-6-4 and 638 S-5-1;2) heterozygotes with only one allele mutated, such as line 638S-1-1 at target site OsNramp5-PS1;3) bi-allelic mutants with both copies of the target sequence mutated differently, including lines HZ-7-3 and 638S4-2 at target site OsNramp5-PS1; and 4) chimeras in which at least 3 distinct target sequences were detected, 
a $\quad 0 s 07 \mathrm{~g} 0257200$

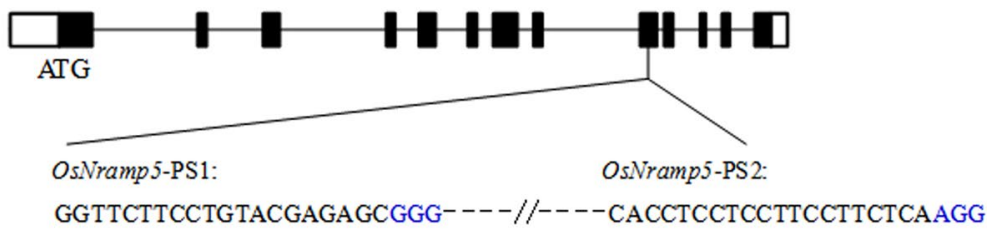

b

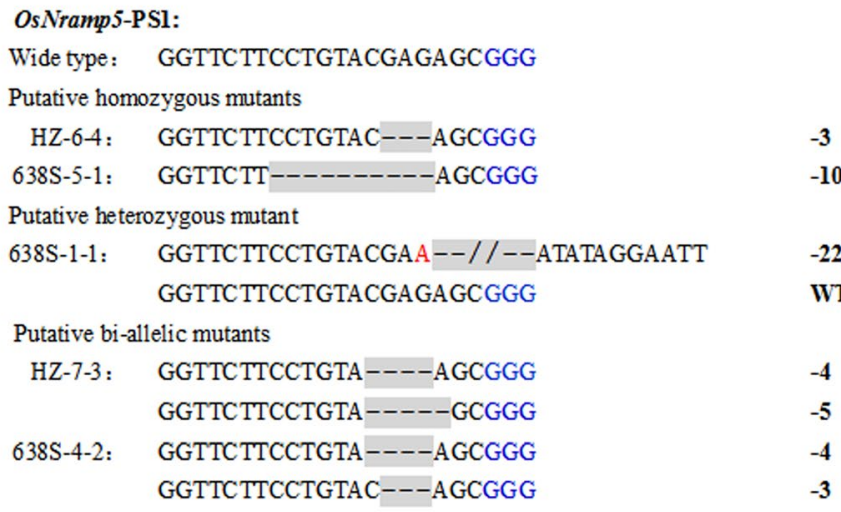

OsNramp5-PS2:

\begin{tabular}{|c|c|c|}
\hline \multicolumn{3}{|c|}{ Putative homozygous mutants } \\
\hline HZ-6-4: & СAССТССТССTTCСTTCTTCAAGG & +1 \\
\hline 638S-5-1: & САССТССТССТТССТ----------------TCATTAТ & -16 \\
\hline \multicolumn{3}{|c|}{ Putative bi-allelic mutant } \\
\hline \multirow[t]{2}{*}{ 638S-1-1: } & GGTTCTTCCTGTACGAA--//--ATATAGGAATT & $-225,+1$ \\
\hline & САССТССТССТTССТTССТСAAGG & +1 \\
\hline \multicolumn{3}{|c|}{ Chimeric mutants } \\
\hline \multirow[t]{4}{*}{ HZ-7-3: } & САССТССТССТTСС---TCAAGG & -3 \\
\hline & САССТССТССТTCСTTCTTCAAGG & $+1 \mathbf{a}$ \\
\hline & CACCTCCTCCTTCCTTCGTCAAGG & $+1 \mathrm{~b}$ \\
\hline & САССТССТССТTCСТTCTCAAGG & WT \\
\hline \multirow[t]{4}{*}{ 638S-4-2: } & САССТССТССТTССТTCATCAAGG & $+1 \mathrm{a}$ \\
\hline & САССТССТССТTССТTСТTCAAGG & $+\mathbf{l b}$ \\
\hline & САССТССТССTTCСTTCGTCAAGG & $+1 \mathrm{c}$ \\
\hline & САССТССТССТТССТTСТСАAGG & WT \\
\hline
\end{tabular}

Figure 1. CRISPR/Cas9-induced mutations in the OsNramp5 gene. (a) Schematic diagram of OsNramp5 gene structure and two CRISPR/Cas 9 target sites. UTRs, exons, and introns are indicated by blank rectangles, black rectangles, and black lines, respectively. The 20-nt target sequences are shown at the bottom of the gene structure, and the following PAMs (NGG) are highlighted in blue. (b) The mutant OsNramp5 genotypes of representative $\mathrm{T}_{0}$ plants are identified by DNA sequencing and alignment. Deletions and insertions are indicated by dashes and red letters, respectively. The numbers on the right side show the sizes of the indels, with "-" and "+" indicating deletion and insertion of the nucleotides involved, respectively. The letters after the numbers represent different bases of the same length.

\begin{tabular}{|c|c|c|c|c|c|c|c|c|c|c|}
\hline \multirow[b]{2}{*}{ Target site } & \multirow[b]{2}{*}{ Host cultivar } & \multirow{2}{*}{$\begin{array}{l}\text { No. of } \\
\text { plants } \\
\text { examined }\end{array}$} & \multirow{2}{*}{$\begin{array}{l}\text { No. of } \\
\text { plants with } \\
\text { mutations }\end{array}$} & \multirow{2}{*}{$\begin{array}{l}\text { Mutation } \\
\text { rate (\%) }\end{array}$} & \multicolumn{2}{|c|}{$\begin{array}{l}\text { Putative } \\
\text { homozygous } \\
\text { mutations }\end{array}$} & \multicolumn{2}{|c|}{$\begin{array}{l}\text { Putative bi-allelic } \\
\text { mutations }\end{array}$} & \multicolumn{2}{|c|}{\begin{tabular}{|l} 
Putative \\
heterozygous \\
mutations
\end{tabular}} \\
\hline & & & & & Number & $\%$ & Number & $\%$ & Number & $\%$ \\
\hline \multirow{2}{*}{ OsNramp5-PS1 } & Huazhan & 17 & 14 & 82.4 & 3 & 17.6 & 9 & 53.0 & 1 & 5.9 \\
\hline & Longke 638S & 10 & 8 & 80.0 & 1 & 10.0 & 6 & 60.0 & 1 & 10.0 \\
\hline \multirow{2}{*}{ OsNramp5-PS2 } & Huazhan & 17 & 12 & 70.6 & 3 & 17.6 & 5 & 29.4 & 1 & 5.9 \\
\hline & \begin{tabular}{|l} 
Longke 638S \\
\end{tabular} & 10 & 7 & 70.0 & 1 & 10.0 & 5 & 50.0 & 0 & 0.0 \\
\hline
\end{tabular}

Table 1. The mutation rates of $\mathrm{T}_{0}$ transgenic plants. 
including lines HZ-7-3 and 638S-4-2 at target site OsNramp5-PS2 (Fig. 1b). Overall, bi-allelic mutations occurred with the highest frequency in the $\mathrm{T}_{0}$ generation (Table 1 ).

Off-target mutations in the CRISPR/Cas9 system have been reported in previous studies ${ }^{46,47}$. To determine whether off-target events were produced in our experiments, we examined 4 putative off-target sites in the rice genome that showed the highest sequence similarity with our target sites. Among all $27 \mathrm{~T}_{0}$ transgenic plants and $30 \mathrm{~T}_{1}$ transgenic plants, no off-target events were found (Supplementary Table 1). These results demonstrate that the sgRNA we designed are of high specificity, and thus we have obtained a high gene editing efficiency with undetectable off-target mutations.

Obtaining homozygous knockout lines free of transgenes in the $\mathrm{T}_{1}$ generation. To further understand the inheritance of mutation, $4 \mathrm{~T}_{0}$ plants and their progeny were investigated. For each $\mathrm{T}_{0}$ plant, 20-38 progeny were sampled randomly and genotyped individually at the two target sites (Supplementary Table 2). As expected, all of the $\mathrm{T}_{0}$ putative homozygotes and their offspring had identical genotypes (HZ-6-4 and 638S-5-1), suggesting that the mutations in these $\mathrm{T}_{0}$ plants were faithfully inherited in the next generation. For the $\mathrm{T}_{1}$ generation of putative bi-allelic mutants (HZ-7-3 and 638S-4-2 at OsNramp5-PS1), the genotype segregation ratio was consistent with Mendelian law, indicating that the targeted mutations in $\mathrm{T}_{0}$ plants were inherited normally. For the $\mathrm{T}_{1}$ generation of chimeras (HZ-7-3 and 638S-4-2 at OsNramp5-PS2), some parental mutations were lost, probably because these mutations took place in parental somatic cells that did not participate in gamete production, and some new mutations were generated, probably due to continuous modification of the wild-type (WT) alleles in Cas9 positive $\mathrm{T}_{1}$ lines.

We also tracked the segregation of transgene (T-DNA) in the $\mathrm{T}_{1}$ population of the $4 \mathrm{~T}_{0}$ plants (Supplementary Table 2), based on a PCR assay of Cas 9 and HPT, which are the elements of T-DNA (Supplementary Fig. 1). The absence of transgenes was determined by negative PCR results of both Cas 9 and HPT. Transgene-free plants were observed in the progeny of all detected $\mathrm{T}_{0}$ plants, with the proportion ranging from $13.6 \%$ to $35.0 \%$ (Supplementary Table 2). These results indicated that transgene-free homozygous mutants could be easily obtained in the $\mathrm{T}_{1}$ generation, as the inheritance of T-DNA and the targeted gene was relatively independent. We isolated 5 transgene-free homozygous knockout lines with coding frame shifts and premature translational stops, including HZ-6-4-6, HZ-7-3-2, HZ-7-3-12, 638S-5-1-4, and 638S-4-2-37, in the $\mathrm{T}_{1}$ generation to produce the $\mathrm{T}_{2}$ population (Fig. 2).

Effect of knocking out OsNramp5 on metal accumulation and major agronomic traits in indica rice. To measure metal accumulation and agronomic traits in the OsNramp5 knockout mutants, the progeny of HZ-64-6, HZ-7-3-2, HZ-7-3-12, and WT plants were cultivated in nutrient solution supplemented with Cd or in soil contaminated by $\mathrm{Cd}$. Metal analysis of seedlings grown in hydroponic culture with $0.5 \mu \mathrm{M}$ or $2.5 \mu \mathrm{MCd}$ showed that both the $\mathrm{Cd}$ and $\mathrm{Mn}$ concentration in shoots and roots was much lower in osnramp5 mutant lines than in WT plants (3.7-13 fold difference of Cd and 1.7-5.6 fold difference of Mn; Fig. 3). Under the toxic condition of $2.5 \mu \mathrm{MCd}$, growth of WT plants was severely inhibited compared with that under no Cd stress, whereas growth of mutant lines was close to that of WT plants under no Cd stress (Fig. 4), indicating that the decrease of Cd in mutants could greatly rescue the reduced growth in the presence of normal-level $\mathrm{Mn}$. In contrast, the concentration of other relevant metals in roots, including iron $(\mathrm{Fe})$, zinc $(\mathrm{Zn})$ and copper $(\mathrm{Cu})$, was not different between the mutants and WT plants (Supplementary Fig. 2d,e,f). In shoots of mutants, the Zn concentration remained essentially unchanged, while the Fe concentration was lower and the $\mathrm{Cu}$ concentration was higher compared with that in shoots of WT plants (Supplementary Fig. 2a,b,c). However, the change in concentrations of Fe and Cu was much less than that for $\mathrm{Cd}$ and $\mathrm{Mn}$.

Mn concentration was mostly decreased among essential micronutrients in osnramp5 mutants, and the great reduction in Mn concentration may affect plant growth. To gain insight into the effect of low Mn supply to growth of osnramp 5 mutants, both mutant and WT plants were grown in normal hydroponic culture for $12 \mathrm{~d}$, and then transferred to nutrient solutions with different low concentrations of Mn for $18 \mathrm{~d}$. Under the condition of no $\mathrm{Mn}$ supply, the mutant lines showed severely stunted growth and yellowing leaves (typical symptoms of Mn deficiency), in contrast to the phenotypes of WT plants. However, the mutants grew similarly to WT plants in the presence of $2 \mu \mathrm{M}$ or higher Mn (Supplementary Fig. 3). These results imply that mutants are tolerant of low Mn conditions to a certain extent.

When mutant plants were grown until maturity in two restricted experimental paddy fields contaminated by different Cd levels $(1.69 \mathrm{mg} / \mathrm{kg}$ and $2.37 \mathrm{mg} / \mathrm{kg}$ ), the Cd concentration in grains (brown rice) was $<0.05 \mathrm{mg} / \mathrm{kg}$, compared with an average of $0.33 \mathrm{mg} / \mathrm{kg}$ and $2.90 \mathrm{mg} / \mathrm{kg}$ in the grains of WT plants (Fig. $5 \mathrm{a}$ ). Similar results were found in the pot with Cd-polluted soil, where the Cd concentration in grains of mutants was also $<0.05 \mathrm{mg} / \mathrm{kg}$, and that of WT was $1.06 \mathrm{mg} / \mathrm{kg}$ (Supplementary Fig. 4). These results suggest that knockout of OsNramp5 could produce low $\mathrm{Cd}$-accumulating rice in high Cd-polluted fields. The analysis of other relevant metals in grains showed that mutants accumulate $34-53 \%$ less Mn than in WT plants (Fig. 5b). Unexpectedly, the concentration of Fe was higher in the mutants (Fig. 5c), but no significant differences in $\mathrm{Cu}$ or $\mathrm{Zn}$ concentration were observed between mutants and WT plants (Fig. 5d and e). In straw, the concentrations of Cd and Mn were much lower in the mutants than in WT plants, and the concentrations of $\mathrm{Fe}, \mathrm{Zn}$, and $\mathrm{Cu}$ were similar between the mutants and WT plants (Supplementary Table 3 and Supplementary Table 4).

Phenotypic analysis showed that there were no visible differences in plant growth or panicle morphologies between the mutant lines and the WT plants (Fig. 6a and b; Supplementary Fig. 5). Moreover, mutant lines exhibited no significant differences in grain yield, straw weight (Fig. 6c and d), grain quality (Supplementary Table 5), or other main agronomic traits (Supplementary Table 6), compared with WT plants. These results demonstrate that knocking out OsNramp5 could have negligible effects on growth, biomass, and main agronomic traits, under our cultivation conditions. 
a

\section{WT}

HZ-6-4-6

HZ-7-3-2

HZ-7-3-12

638S-5-1-4

$638 \mathrm{~S}-4-2-37$

b

พI

$\mathrm{Hz}-6-4-6$

$638 s-4-2-3$

H2 -7-3-12

$638 \mathrm{~S}-5-1-4$

$\mathrm{HZ}-7-3-2$

พT

$\mathrm{Hz}-6-4-6$

$6385-4-2-3$

Hz $-7-3-12$

$638 \mathrm{~S}-5-1-4$

$\mathrm{Hz}-7-3-2$

พบ

$\mathrm{Hz}-6-4-6$

$6385-4-2-3$

Hz $-7-3-12$

$6385-5-1-4$

$\mathrm{HZ}-7-3-2$

WI

$\mathrm{Hz}-6-4-6$

$6385-4-2-3$

Hz $-7-3-12$

$6385-5-1-4$

$\mathrm{HZ}-7-3-2$

WI

Hz-6-4-6

$638 S-4-2-3$

H2 $-7-3-12$

$638 \mathrm{~S}-5-1-4$

$\mathrm{Hz}-7-3-2$

พT

Hz-6-4-6

$6385-4-2-3$

Hz-7-3-12

$638 S-5-1-4$

$\mathrm{Hz}-7-3-2$
OsNramp5-PS1

GGTTCTTCCTG TACGAGAGCGGG

GGTTCTTCCTG TAC---AG CGG G

GGTTCTTCCTGTA-----GCGGG

GGTTCTTCCTGTA----AGCGGG

GGTTCTT---------AGCGGG

GGTTCTTCCTGTAC---AGCGGG
OsNranp5-PS2

СACСTCСTCCTTCCTTCTCAAG G

CACCTCCTCCTTCCTTCTTCAAGG $-3,+1$

CACCTCCTCCTTCCTTCTCAAGG -5 , WT

САССТССТССТСC---TCAAGG $-4,-3$

CACCTCCTCCTTCCT-------------TCATTAT $-10,-16$

CACCTCCTCCTTCCTTCATCAAGG

$-3,+1$
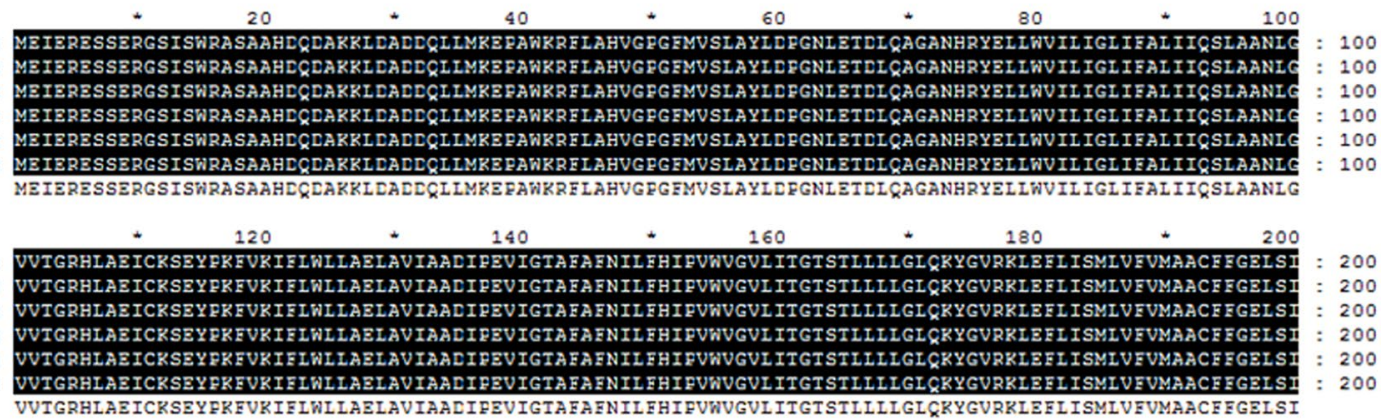

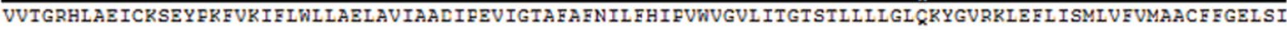

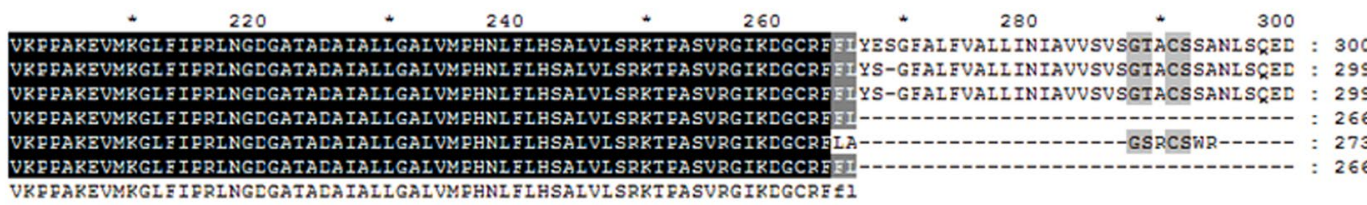
VRFFAREVMRGI IFRINGLGATADAIALIGALVMFHNI ILHSALVISRKIFASVRGIKEGCREEI

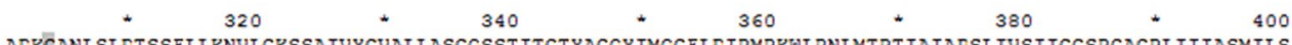
DDSIVSIIGGSRGAGRIIIIASMIIS : 400

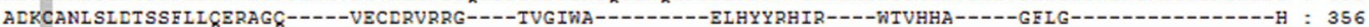

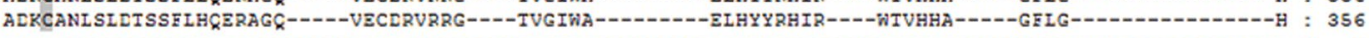

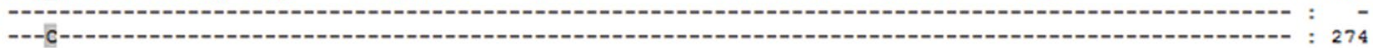
(420 440 460 480 500 FELFFAIIFLIKFSSSRSKMGFHKNSIYIIVFSWFLGLIIIGINMYFLSTSFVGWLIHNDLFRYANVIVGAAVFPFMIVYIVAVVYITIRKDSVVTFVAD : SOO

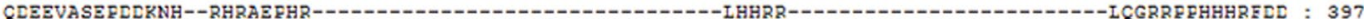

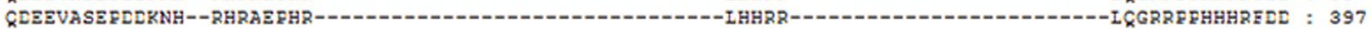
KLEEVASEFLEKNH--RHRAEFHR--1 520

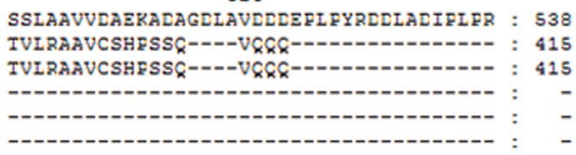

Figure 2. Homozygous osnramp5 mutants induced by CRISPR/Cas9. (a) DNA sequence alignments for the 5 homozygous osnramp 5 mutants identified in the $\mathrm{T}_{1}$ generation, together with a wild-type (WT) control. The numbers on the right side are the sizes of the indels, with "-" and "+" showing deletion and insertion of nucleotides involved, respectively. (b) Deduced OsNramp5 amino acid sequence alignments for the 5 homozygous mutants and WT. Each of the mutant alleles codes for truncated and disrupted OsNramp5 proteins.

Development of promising hybrid rice lines with extremely low Cd content in grains. We developed two independent mutant hybrid rice lines (P12-1, P12-2) by crossing the 638S mutants (638S-5-1-4, 638S4-2-37) and HZ mutants (HZ-6-4-6, HZ-7-3-12), respectively. The hybrid rice line P12-C generated by crossing WT 638S and HZ mutant (HZ-6-4-6) served as a control. These mutants and WT LLYHZ plants were grown in the experimental paddy field with $2.37 \mathrm{mg} / \mathrm{kg} \mathrm{Cd}$ in soil. Metal analysis showed that Cd concentration in grains of mutant lines (P12-1, P12-2) was decreased by more than $98 \%(<0.05 \mathrm{mg} / \mathrm{kg})$ and the Mn concentration was reduced by $41 \%$ compared with WT plants. However, there was no significant difference in the concentrations of $\mathrm{Fe}, \mathrm{Zn}$, or $\mathrm{Cu}$ in grains between the mutant lines (P12-1, P12-2) and WT plants (Fig. 7a). In contrast, concentrations of all five metals in the grains of P12-C were similar to that of WT plants (Fig. 7a), suggesting that metal content was changed only when both of the parental lines were mutated. In addition, there was no obvious difference in plant morphology, grain yield, or straw weight between the mutant lines and WT plants (Fig. 7b-d). These 
a

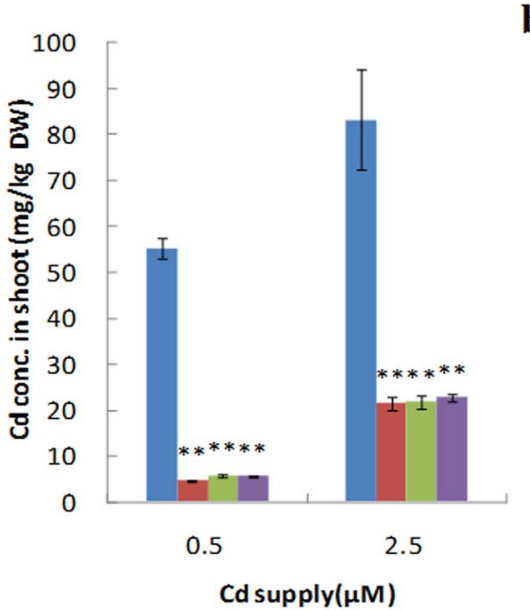

c

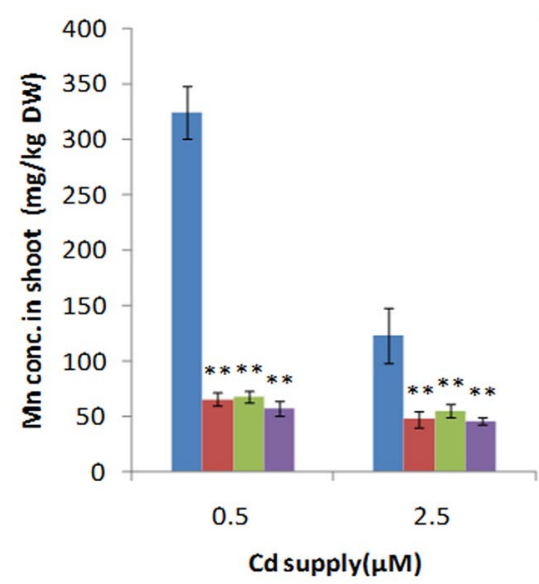

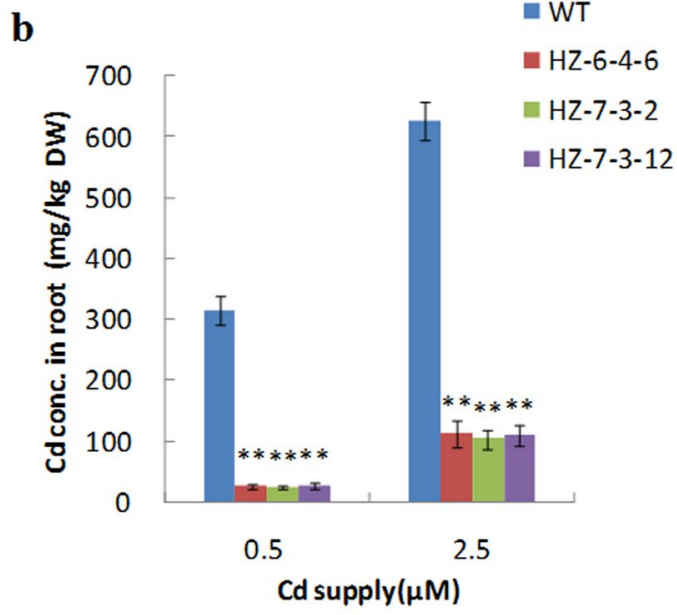

d

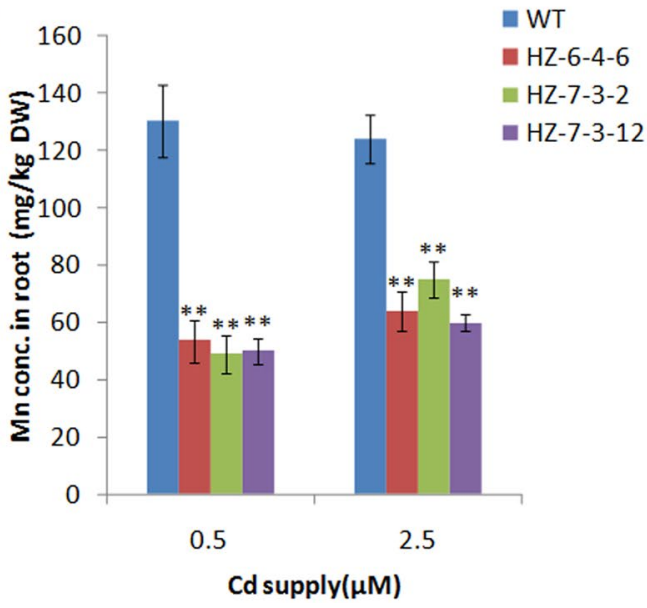

Figure 3. Concentrations of $\mathrm{Cd}$ and $\mathrm{Mn}$ in shoots and roots at different $\mathrm{Cd}$ levels. Three osnramp5 mutant lines (HZ-6-4-6, HZ-7-3-2, HZ-7-3-12) and WT plants (HZ) were grown in normal nutrient solution for 2 weeks and then transferred to the nutrient solution containing 0.5 or $2.5 \mu \mathrm{MCd}$ for another 2 weeks. The shoots and roots were harvested and subjected to mineral analysis by inductively coupled plasma optical emission spectrometry (ICP-OES). (a and b) Cd concentrations in the shoots (a) and roots (b). (c and d) Mn concentrations in the shoots (c) and roots (d). DW, dry weight. Data are means \pm SD of three biological replicates, and three plants were mixed in one replication for metal determination. Two asterisks indicate statistically significant difference in comparison to WT at $P<0.01$ by Student's $t$ test.

results demonstrate that the knockout of OsNramp5 by the CRISPR/Cas9 system could be applied to two-line indica hybrid breeding, developing Cd pollution-safe hybrids suitable for planting in high Cd paddy fields.

\section{Discussion}

There is a worldwide concern about Cd contamination in rice grains, and thus lowering grain Cd content is critical, but still challenging. In the present study, OsNramp5 was knocked out using the CRISPR/Cas9 system, in the popular male sterile line $638 \mathrm{~S}$ and restorer line $\mathrm{HZ}$ of indica hybrid rice. In addition, the mutant hybrid LLYHZ was developed by crossing the mutant parental lines. The osnramp5 mutants and their hybrids had nearly undetectable levels of $\mathrm{Cd}$ in the grains, and yield and main agronomic traits were not affected when they were grown in Cd-contaminated paddy fields. These phenotypes were similar to that of the osnramp5 mutant with the Koshihikari background ${ }^{21}$. In contrast, the growth and yield of the T-DNA insertion mutant of OsNramp5 with Zhonghua 11 background were heavily influenced ${ }^{20}$. The inconsistent effect of OsNramp 5 mutation on plant yield probably arises from different $\mathrm{Mn}$ concentration in mutants caused by differences in mutation sites, genetic backgrounds, or supplies of Mn.

$\mathrm{Mn}$ is an essential micronutrient for plant growth and development, and thus Mn deficiency could result in lower yield in osnramp5. Mn concentrations in the shoots/straws were much higher in HZ and LLYHZ knockout mutants than in the Zhonghua11 knockout mutant, in both normal hydroponic culture and soil culture (Fig. 3c, Supplementary Table 3 and Supplementary Table 4) ${ }^{20}$. In addition, Mn concentrations in straws of HZ and LLYHZ knockout mutants grown in the paddy fields were decreased by $80.6-82.6 \%$ compared with WT plants, and were either higher than or close to $150 \mathrm{mg} / \mathrm{kg}$ (Supplementary Table 3 and Supplementary Table 4). 
a

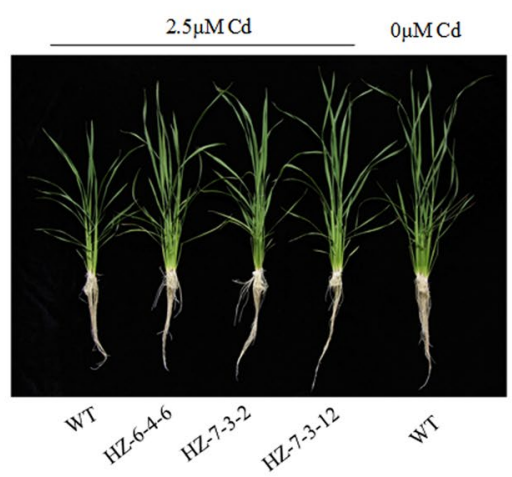

c

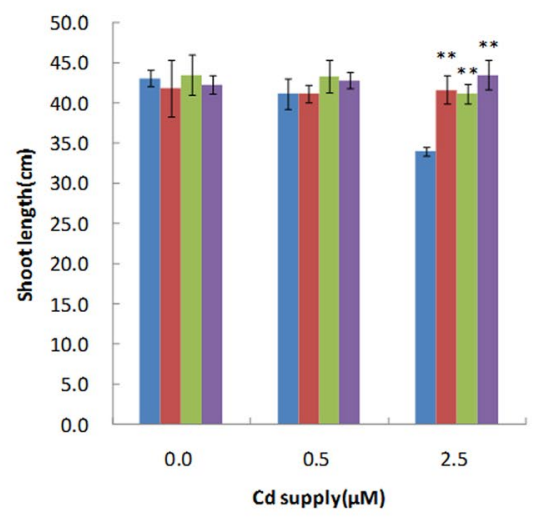

b

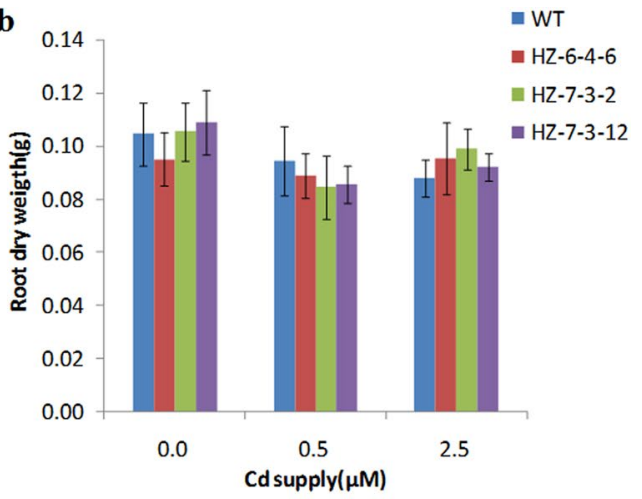

d

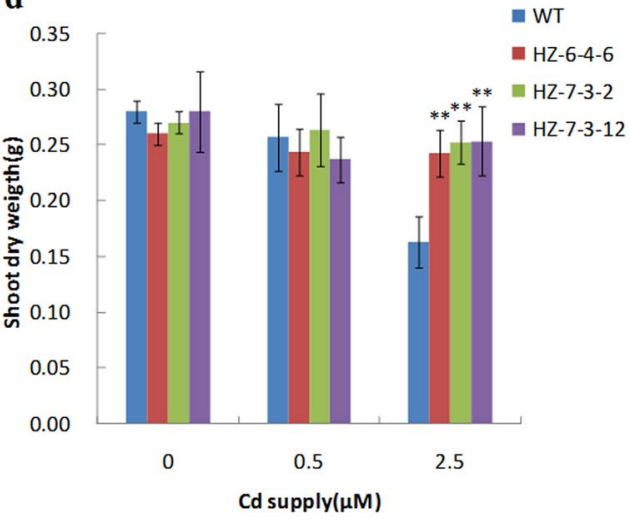

Figure 4. Phenotypic analysis of osnramp5 mutants at different Cd levels. Three mutant lines (HZ-6-4-6, HZ-7-3-2, HZ-7-3-12) and WT plants (HZ) were cultivated in normal nutrient solution for 2 weeks and then transferred to the nutrient solution containing 0.5 or $2.5 \mu \mathrm{M} \mathrm{Cd}$ for another 2 weeks. (a) Plant morphologies of the mutant lines and WT in response to $2.5 \mu \mathrm{M}$ Cd exposure. (b) Root dry weight. (c) Shoot length. (d) Root dry weight. Data are means \pm SD of three biological replicates, and three plants were mixed in one replication. Two asterisks indicate statistically significant difference in comparison to WT at $P<0.01$ by Student's $t$ test.

This level of Mn concentration was high enough to cause toxic symptoms in barley ${ }^{48}$. In contrast, the Mn concentration in straw of the Zhonghua 11 knockout mutant grown in soil culture was approximately 95\% less than that in WT plants ${ }^{20}$. On the other hand, the HZ knockout mutants probably require less $\mathrm{Mn}$ for normal growth than the Zhonghua 11 knockout mutant. Here, we performed hydroponic culture with a method similar to that used by Yang et al. ${ }^{49}$, except with a different Mn concentration gradient. Mn concentration in the shoots of the HZ knockout mutant $(2 \mu \mathrm{M}$ Mn supplied) was close to that in the Zhonghua 11 knockout mutant (1.6 $\mu \mathrm{M}$ Mn supplied) (Supplementary Table 7) ${ }^{49}$. However, the HZ knockout mutant had a similar phenotype to WT plants, whereas the Zhonghua 11 knockout mutant showed reduced growth (Supplementary Fig. 3) ${ }^{49}$. It has been described that the critical deficiency concentrations of $\mathrm{Mn}$ in plants are similar, varying between 10 and $20 \mathrm{mg} / \mathrm{kg}$ dry weight in fully expanded leaves ${ }^{50}$. Mn concentrations in the shoots of both the HZ knockout mutant and Zhonghua 11 knockout mutant were within this range. It is likely that the higher Mn concentration in straws of HZ knockout mutants and their lower sensitivity to low-Mn concentration, caused the different influence on their yield compared with that of Zhonghua11 knockout mutant.

In contrast to other crops, rice is usually cultivated under flooded conditions, where is anaerobic and Mn concentration is generally high. Rice has developed strategies to accumulate high $\mathrm{Mn}$ without symptoms of toxicity ${ }^{48}$. It is possible that the growth of osnramp 5 mutants would not be inhibited, when mutants were cultivated in Cd-polluted soils with a low Mn concentration, by applying Mn fertilizer or prolonging flooded time properly, due to greatly increased bioavailability of $\mathrm{Mn}$ under flooded conditions ${ }^{51}$. The effects of knocking out OsNramp5 on $\mathrm{Mn}$ concentration in shoots, on plant growth, and on main agronomic traits under gradient low-Mn field conditions need to be studied further in various rice cultivars with multiple genetic backgrounds.

The markedly lower accumulation of $\mathrm{Mn}$ and $\mathrm{Cd}$ in the osnramp5 mutant in the present study supports the crucial role of OsNramp5 for $\mathrm{Mn}$ and Cd uptake ${ }^{20,52}$. In addition, increasing Cd in the external solution decreased Mn accumulation in shoots of WT plants, while this effect was not obvious in osnramp5 mutants (Fig. 3c). This result implies that $\mathrm{Mn}$ and $\mathrm{Cd}$ compete for uptake mediated by the OsNramp5 transporter, and an abundance of one metal could disturb the uptake of the other. Rice is a staple food crop with high Mn accumulation, and the majority of $\mathrm{Mn}$ is taken up by OsNramp $5^{20}$. It seems likely that external Cd competitively enters the root cells during the process of OsNramp5 mediating uptake of Mn from the soil, as OsNramp5 has limited substrate specificity. Genotypic variation of Cd accumulation between two rice subspecies, japonica and indica, has been reported ${ }^{1-14}$, but little is known about the molecular mechanism. As OsNramp5 contributes greatly to Cd 
a

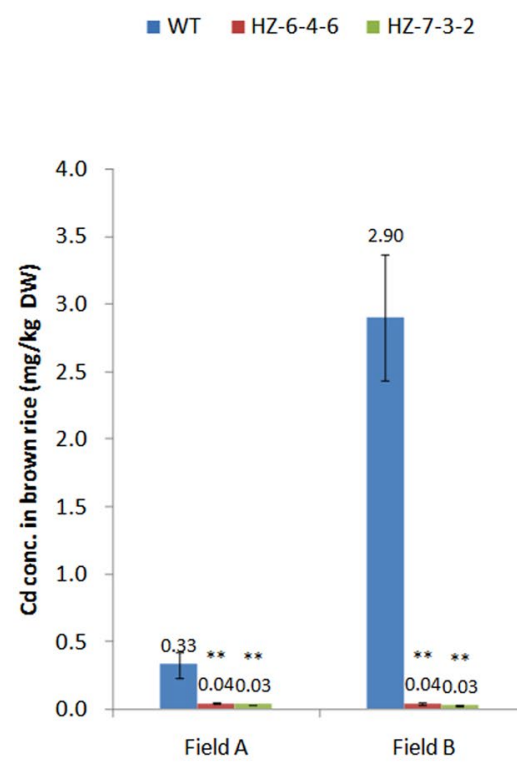

b

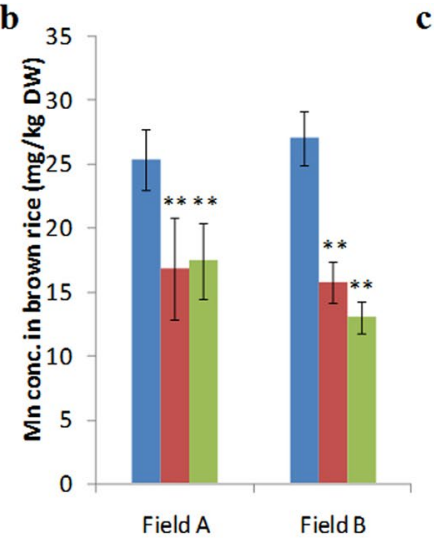

d

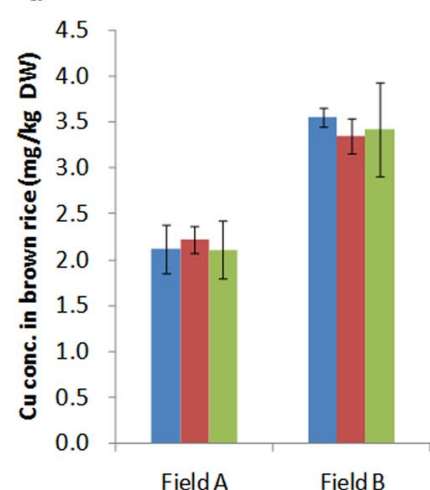

c

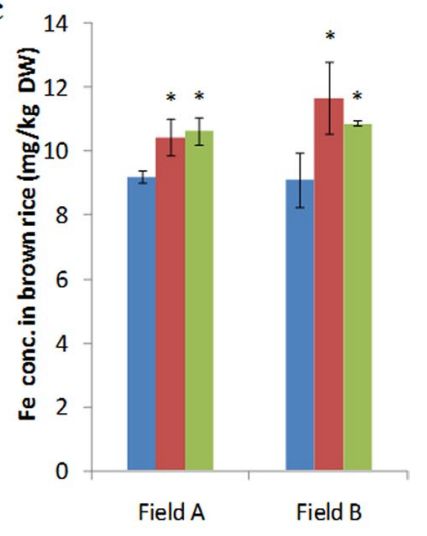

$\mathbf{e}$

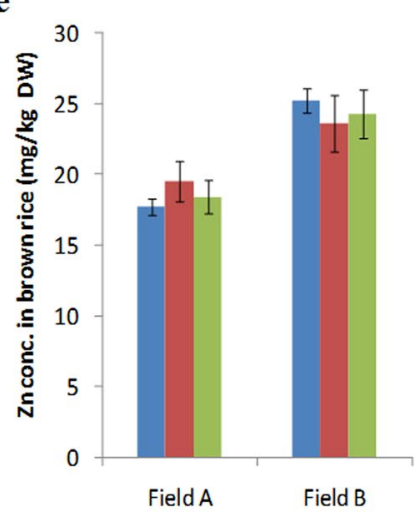

Figure 5. Metal concentrations in the brown rice of osnramp 5 mutants. Two mutant lines (HZ-6-4-6, HZ7-3-2) and WT plants (HZ) were cultivated together in two restricted experimental paddy fields containing $1.69 \mathrm{mg} / \mathrm{kg}$ (Field A) and $2.37 \mathrm{mg} / \mathrm{kg}$ (Field B) Cd in the soil, respectively. (a) Cd, (b) Mn, (c) Fe, (d) Cu and (e) Zn concentrations in brown rice were determined by ICP-OES. DW, dry weight. Data are means \pm SD of three biological replicates, and grains of three plants were mixed in one replication. One or two asterisks indicate statistically significant difference in comparison to WT at $P<0.05$ or $P<0.01$ by Student's $t$ test.

accumulation in rice, further analysis is needed to determine whether there is a difference in the expression level of OsNramp 5 between indica and japonica rice, and whether there is a positive correlation between the expression level of $\mathrm{OsNramp5}$ and the $\mathrm{Cd}$ content in rice.

It has been reported that knockdown of OsNramp 5 could lead to more $\mathrm{Cd}$ accumulation in shoots of RNAi lines than WT plants, making it a promising candidate for phytoremediation in paddy fields ${ }^{52,53}$. However, OsNramp 5 RNAi knockdown lines generated by Sasaki et al. ${ }^{20}$, as well as OsNramp 5 knockout lines in our study and other previous studies ${ }^{20,21,49}$, accumulated much less $\mathrm{Cd}$ in shoots than WT plants. This contradictory effect is not likely to arise from the direct role of OsNramp5. There is strong evidence that $\mathrm{Cd}$ and $\mathrm{Fe}$ share transporters in rice, such as OsIRT1, OsIRT2, OsNramp1, and OsNramp 520,22,23. The expression of some Fe/Cd transporter genes were highly induced in OsNramp 5 knockout or knockdown lines, especially under the condition of $\mathrm{Fe}$ (II) deficiency ${ }^{49,52,53}$. The increased expression of these $\mathrm{Fe} / \mathrm{Cd}$ transporters enhanced $\mathrm{Cd}$ translocation from root to shoot ${ }^{22,52}$. The expression of OsNramp 5 in Anjana Dhan RNAi lines was suppressed only by 1/3 to $1 / 2$ of that in WT plants ${ }^{53}$, so the decreased amount of Cd in shoots by suppression of OsNramp 5 would be less than the increased amount of Cd by induction of other $\mathrm{Fe} / \mathrm{Cd}$ transporters, giving rise to higher $\mathrm{Cd}$ concentrations in shoots of RNAi lines. But the degree of decrease in $\mathrm{Cd}$ amount in shoots was very serious, when the structure of OsNramp5 protein was broken down in knockout lines ${ }^{21}$, or when the expression of OsNramp 5 was extremely suppressed in knockdown lines ${ }^{20}$, which cannot be complemented by an increase in $\mathrm{Cd}$ translocation through other $\mathrm{Fe} / \mathrm{Cd}$ transporters.

In conclusion, we evaluated the effects of OsNramp 5 mutation on accumulation of $\mathrm{Cd}$ and relevant metals, and on main agronomic traits in indica rice using CRISPR/Cas9-mediated mutagenesis. The high $\mathrm{Cd}$ accumulation trait of indica rice was modified quickly, effectively, and conveniently, whereas yield and main agronomic traits were not impaired. Transgenes were segregated out through selfing, creating genome-edited mutant plants that were free of transgenes. These plants were not different from plants carrying spontaneous mutations or mutations induced by physical and chemical treatment, in addition to the advantage that the precise mutation reduced the risk of introducing undesired traits ${ }^{41,54}$. Thus, these genome-edited mutants could circumvent public and governmental concerns about introduced persistent transgenes or other unwanted genomic fragments. Our study developed promising indica rice lines and their hybrids with extremely low $\mathrm{Cd}$ content in grains and without compromising yield using the CRISPR/Cas9 mediated OsNramp5 editing system. This approach can be used to 
a

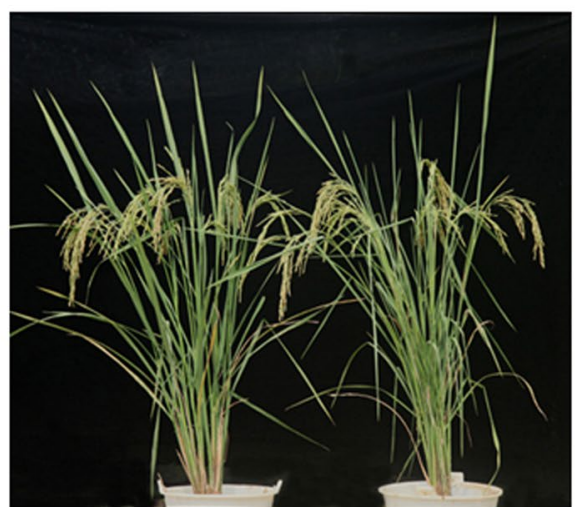

WT

b

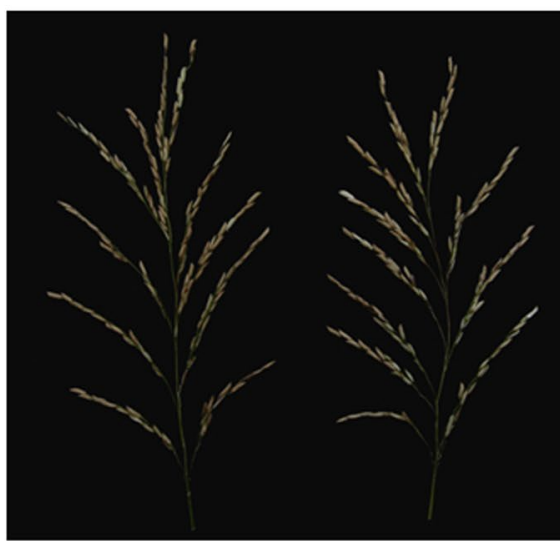

WT
$\mathrm{HZ}-7-3-2$

$\mathrm{HZ}-7-3-2$

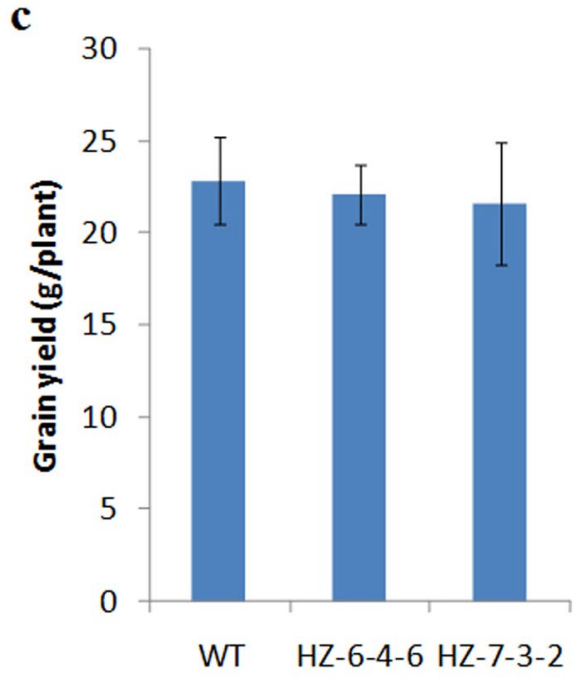

d

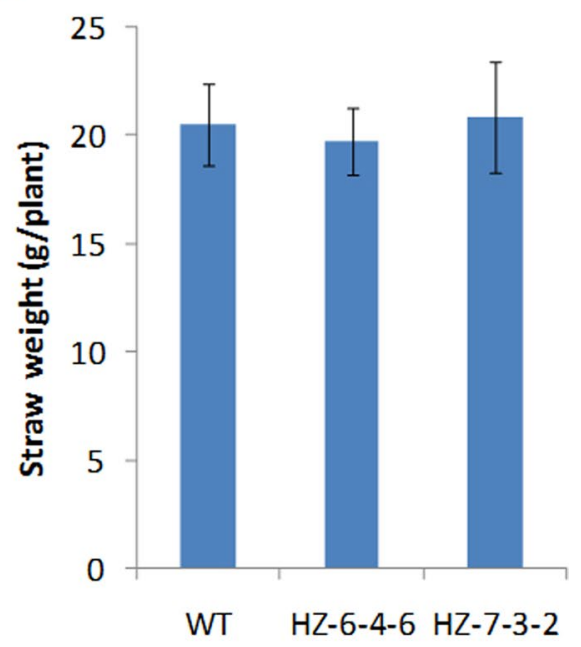

Figure 6. Morphology and yield analysis of osnramp5 mutants. Two mutant lines (HZ-6-4-6, HZ-7-3-2) and WT plants (HZ) were cultivated in the Cd contaminated experimental field (Field A). (a) Plant morphology. (b) Panicle morphology. (c) Grain yield. (d) Straw dry weight. There is no significant difference between WT and mutant lines in grain yield and straw dry weight according to Student's $t$ test.

reduce grain Cd levels in other widespread indica rice cultivars, facilitating the development of precision breeding targeted at Cd pollution-safe rice.

\section{Methods}

Vector construction and rice transformation. The Cas9 plant expression vector (pYLCRISPR/ Cas9Pubi-H) and sgRNA expression vector (pYLgRNA) were provided by Prof. Yao-Guang Liu (South China Agricultural University). According to the design principles of the target sequences in the CRISPR/Cas9 system, 19 to 20 bases upstream of the PAM motif were selected as candidate target sequences. A BLAST search (http://blast. ncbi.nlm.nih.gov/Blast.cgi) of the target sequences (including PAM) against the rice genome was carried out to confirm their targeting specificity in the genome. CRISPR/Cas9 plant expression vectors were constructed as previously described ${ }^{45}$, based on Golden Gate cloning. Binary constructs were then introduced into Agrobacterium tumefaciens strain EHA105. Popular parental lines of indica hybrid rice (Oryza sativa L. cv. Huazhan and Longke 638S) were used for plant transformation. Agrobacterium-mediated transformations of embryogenic calli were performed by Wuhan Biorun biological technology Co., Ltd. After 4 weeks of rooting, regenerated rice plants were transferred to plastic buckets in a greenhouse maintained at $30^{\circ} \mathrm{C}$ during the day and $26^{\circ} \mathrm{C}$ at night.

Mutation detection and assay of transgene-free plant lines. Genomic DNA was extracted from at least 5 leaves of different tillers during the rice maturity period using the cetyltrimethyl ammonium bromide (CTAB) method $^{55}$. PCR was performed to amplify the genomic region containing the CRISPR/Cas9 target sites using specific primers (Supplementary Table 8 ). The PCR products were purified and directly sequenced. If the sample produced superimposed sequence chromatograms, it was cloned into the pEASY-Blunt (Trans Gen 
$\mathbf{a}$

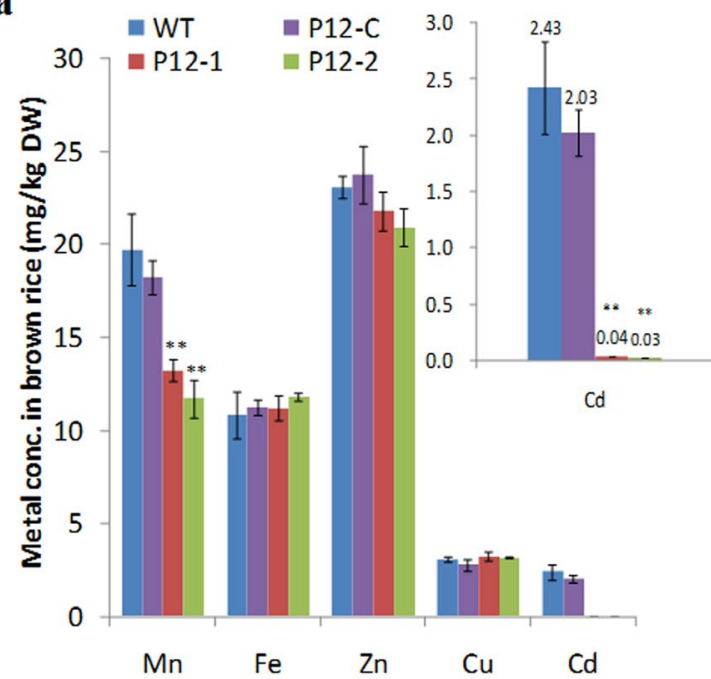

b

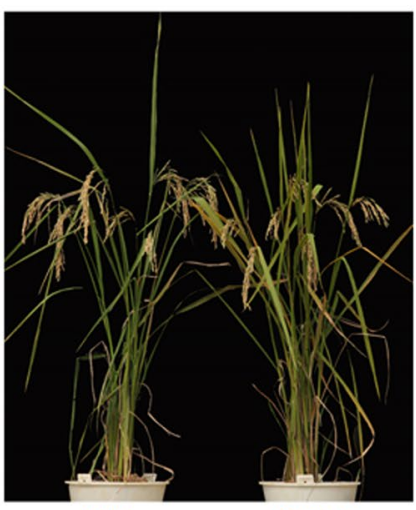

WT

P12-1
C

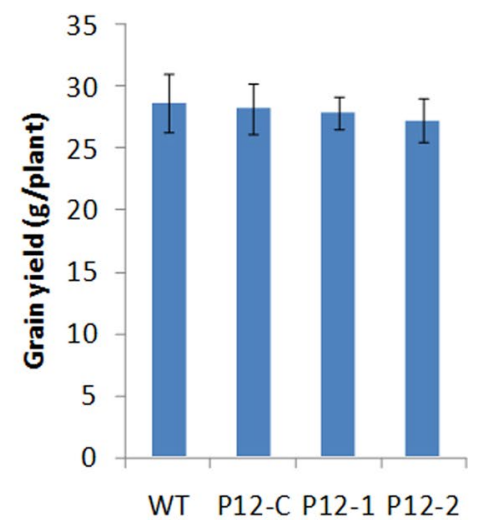

d

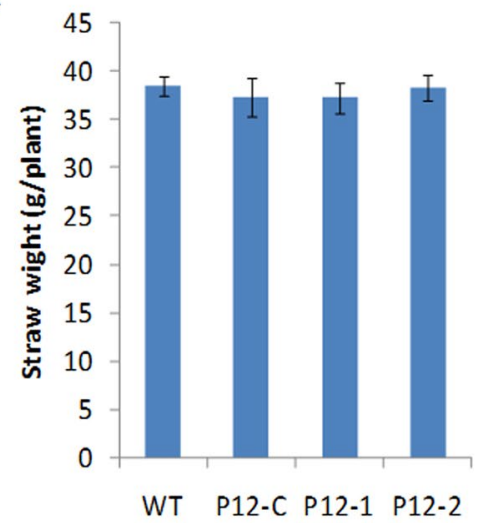

Figure 7. Morphology and yield analysis of mutant hybrid rice lines. Two osnramp5 mutant hybrid rice lines (P12-1, P12-2), control line (P12 C) and WT plants (LLYHZ) were cultivated in the highly Cdcontaminatedexperimental field (Field B). (a) Metal concentration in brown rice. (b) Plant morphology. (c) Grain yield. (d) Straw dry weigh. DW, dry weight. Two asterisks indicate statistically significant difference in comparison to WT at $P<0.01$ by Student's $t$ test.

Biotech, Beijing, China), and at least 10 clones were sequenced to identify the genotype of the mutation. Multiple amino acid sequence alignments were performed using ClustalX2 ${ }^{56}$ and displayed using GeneDoc software (http://www.softpedia.com/get/Science-CAD/GeneDoc.shtml\#download).

The identification of transgene-free plants was conducted using $\mathrm{T}_{1}$ generation plants. The plants were analysed by PCR using HPT-specific and Cas9-specific primers (Supplementary Table 8) and agarose gel electrophoresis. The CRISPR/Cas9 plasmid targeting OsNramp5 and the $\mathrm{T}_{0}$ transgenic plants were selected as positive controls, and $\mathrm{HZ}$ or $638 \mathrm{~S}$ and $\mathrm{H}_{2} \mathrm{O}$ were used as negative controls. HPT- and Cas9-negative plants were considered transgene-free plants.

Hydroponic experiments. Seedlings of three independent mutant lines and WT plants were grown hydroponically in rice culture solution described by Yoshida et al..$^{57}$. The plants were grown in a greenhouse at $26^{\circ} \mathrm{C}$ to $30^{\circ} \mathrm{C}$ under natural light. The culture solution was renewed every $3 \mathrm{~d}$. In the $\mathrm{Cd}$ treatment experiments, plants were cultivated in normal nutrient solution for $14 \mathrm{~d}$ and then transferred to the nutrient solution containing 0.5 or $2.5 \mu \mathrm{MCd}$ (added as $\mathrm{CdCl}_{2}$ ) for another $14 \mathrm{~d}$. The roots were washed three times with deionized water and separated from the shoots, and subjected to metal concentration determination as described below. In the low Mn concentration gradient experiments, plants were grown in normal nutrient solution for $12 \mathrm{~d}$, and then transferred to the nutrient solution with $0,2,4$, or $6 \mu \mathrm{M} \mathrm{Mn}$ (lower than normal culture) for $18 \mathrm{~d}$. Three biological replicates were used for each treatment.

Field and pot experiments. The independent mutant lines and WT plants were cultivated in different Cd-polluted experimental paddy fields in China. The soil Cd concentrations were $1.69 \mathrm{mg} / \mathrm{kg}$ in field A, $2.37 \mathrm{mg} / \mathrm{kg}$ in field B and $1.53 \mathrm{mg} / \mathrm{kg}$ in field C; the soil Mn concentrations were $246 \mathrm{mg} / \mathrm{kg}$ in field A, $162 \mathrm{mg} / \mathrm{kg}$ in field B and $849 \mathrm{mg} / \mathrm{kg}$ in field $\mathrm{C}$; and the soil pH values were 5.1 in field A, 5.5 in field B and 6.1 in field C. 28-day-old seedlings were transplanted into the flooded field plots, with one plant per hill, spaced at $20 \mathrm{~cm} \times 20 \mathrm{~cm}$. The plot for each line 
included 4 rows, with a total of 40 plants. The fields were irrigated intermittently until grain maturity. We applied inorganic fertilizers containing $\mathrm{N}, \mathrm{K}$, and $\mathrm{P}$ using standard methods. After grains were harvested, metal concentration and major agronomic traits, including grain yields and straw weight, were analysed. Rice quality was measured using the standard of NY/T 593-2013 published by the Rice Product Quality Supervision and Inspection Centre, Ministry of Agriculture, China (http://www.zbgb.org/27/StandardDetail1476335.htm). The field experiments were arranged in a randomized complete block design with three plot replications. In pot experiments, 28-day-old seedlings were transplanted into plastic pots filled with polluted paddy soil with $1.31 \mathrm{mg} / \mathrm{kg} \mathrm{Cd}$ and $259 \mathrm{mg} / \mathrm{kg} \mathrm{Mn}$ concentration, with a $\mathrm{pH}$ value of 5.7. Plants were grown in a greenhouse at 26 to $30^{\circ} \mathrm{C}$ under natural light, with three biological replicates. Tap water was supplied intermittently throughout the cultivation.

Metal concentration determination. Shoots, roots, and brown rice samples were harvested and dried at $70^{\circ} \mathrm{C}$ for $2 \mathrm{~d}$. The dried samples were ground into powder and digested with an acid mixture of $\mathrm{HNO}_{3}-\mathrm{HClO}_{4}$ $(6: 1, \mathrm{v} / \mathrm{v})$, and then placed on an electric heating plate for digestion until they were almost completely evaporated. After cooling, the residues were dissolved in $1 \% \mathrm{HNO}_{3}(1: 10, \mathrm{v} / \mathrm{v})$ and filtered. The filtered solutions were diluted to $10 \mathrm{~mL}$ for brown rice samples, and $25 \mathrm{~mL}$ for shoot and root samples. Then, the metal concentration was determined by inductively coupled plasma optical emission spectrometry (SPS3 ICP-720 OES; Agilent Technologies) at the following wavelengths: $226.502(\mathrm{Cd}), 293.305(\mathrm{Mn}), 238.204(\mathrm{Fe}), 206.200(\mathrm{Zn})$, and $324.754(\mathrm{Cu}) \mathrm{nm}$.

\section{References}

1. Clemens, S., Aarts, M. G., Thomine, S. \& Verbruggen, N. Plant science: the key to preventing slow cadmium poisoning. Trends Plant Sci 18, 92-99 (2013).

2. Uraguchi, S. \& Fujiwara, T. Rice breaks ground for cadmium-free cereals. Curr Opin Plant Biol 16, 328-334 (2013).

3. Bertin, G. \& Averbeck, D. Cadmium: cellular effects, modifications of biomolecules, modulation of DNA repair and genotoxic consequences. Biochimie 88, 1549 (2006).

4. Yuan, L. P. Development of hybrid rice to ensure food security. Rice Science 21, 1-2 (2014).

5. Hu, Y., Cheng, H. \& Tao, S. The challenges and solutions for cadmium-contaminated rice in China: A critical review. Environ Int 92-93, 515-532 (2016).

6. Jallad, K. N. Heavy metal exposure from ingesting rice and its related potential hazardous health risks to humans. Environ Sci Pollut Res Int 22, 15449-15458 (2015).

7. Shraim, A. M. Rice is a potential dietary source of not only arsenic but also other toxic elements like lead and chromium. Arabian Journal of Chemistry, 1-10 (2014).

8. Meharg, A. A. et al. Variation in rice cadmium related to human exposure. Environ Sci Technol 47, 5613-5618 (2013).

9. Honda, R. et al. Cadmium induced renal dysfunction among residents of rice farming area downstream from a zinc-mineralized belt in Thailand. Toxicol Lett 198, 26-32 (2010).

10. Watanabe, T., Shimbo, S., Moon, C. S., Zhang, Z. W. \& Ikeda, M. Cadmium contents in rice samples from various areas in the world. Sci Total Environ 184, 191-196 (1996).

11. Arao, T. \& Ae, N. Genotypic variations in cadmium levels of rice grain. Soil Science \& Plant Nutrition 49, 473-479 (2003).

12. Arao, T. \& Ishikawa, S. Genotypic differences in cadmium concentration and distribution of soybean and rice. Jarq Japan Agricultural Research Quarterly 40, 21-30 (2006).

13. Uraguchi, S. et al. Root-to-shoot Cd translocation via the xylem is the major process determining shoot and grain cadmium accumulation in rice. J Exp Bot 60, 2677 (2009).

14. Grant, C. A., Clarke, J. M., Duguid, S. \& Chaney, R. L. Selection and breeding of plant cultivars to minimize cadmium accumulation. Sci Total Environ 390, 301-310 (2008).

15. Uraguchi, S. \& Fujiwara, T. Cadmium transport and tolerance in rice: perspectives for reducing grain cadmium accumulation. Rice 5, 5 (2012).

16. Ebbs, S. D. et al. Phytoextraction of cadmium and zinc from a contaminated soil. Journal of Environmental Quality 26, 1424-1430 (1997).

17. Arao, T., Ishikawa, S., Murakami, M. \& Abe, K. Heavy metal contamination of agricultural soil and counter measures in Japan. Paddy \& Water Environment 8, 247-257 (2010).

18. Huang, S. et al. Evaluation of the effects of lime-bassanite-charcoal amendment on the immobilization of cadmium in contaminated soil. Bull Environ Contam Toxicol 1-6 (2016).

19. Fujimaki, S. et al. Tracing cadmium from culture to spikelet: noninvasive imaging and quantitative characterization of absorption, transport, and accumulation of cadmium in an intact rice plant. Plant Physiol 152, 1796-1806 (2010).

20. Sasaki, A., Yamaji, N., Yokosho, K. \& Ma, J. F. Nramp5 is a major transporter responsible for manganese and cadmium uptake in rice. Plant Cell 24, 2155-2167 (2012).

21. Ishikawa, S. et al. Ion-beam irradiation, gene identification, and marker-assisted breeding in the development of low-cadmium rice. Proc Natl Acad Sci USA 109, 19166-19171 (2012).

22. Nakanishi, H., Ogawa, I., Ishimaru, Y., Mori, S. \& Nishizawa, N. K. Iron deficiency enhances cadmium uptake and translocation mediated by the $\mathrm{Fe}^{2+}$ transporters OsIRT1 and OsIRT2 in rice. Soil Science \& Plant Nutrition 52, 464-469 (2006).

23. Senoura, T., Shimo, H., Ishikawa, S. \& Nishizawa, N. K. The OsNRAMP1 iron transporter is involved in Cd accumulation in rice. J Exp Bot 62, 4843-4850 (2011).

24. Ueno, D., Koyama, E., Yamaji, N. \& Ma, J. F. Physiological, genetic, and molecular characterization of a high-Cd-accumulating rice cultivar, Jarjan. J Exp Bot 62, 2265-2272 (2011).

25. Ueno, D. et al. Gene limiting cadmium accumulation in rice. Proc Natl Acad Sci USA 107, 16500 (2010).

26. Satoh-Nagasawa, N. et al. Mutations in rice (Oryza sativa) heavy metal ATPase 2 (OsHMA2) restrict the translocation of zinc and cadmium. Plant Cell Physiol 53, 213-224 (2012).

27. Takahashi, R. et al. The OsHMA2 transporter is involved in root-to-shoot translocation of Zn and Cd in rice. Plant Cell Environ 35 , 1948-1957 (2012).

28. Uraguchi, S. et al. Low-affinity cation transporter (OsLCT1) regulates cadmium transport into rice grains. Proc Natl Acad Sci USA 108, 20959-20964 (2011).

29. Su, N. et al. Disruption of a rice pentatricopeptide repeat protein causes a seedling-specific albino phenotype and its utilization to enhance seed purity in hybrid rice production. Plant Physiol 159, 227 (2012).

30. Zhou, H. et al. Development of commercial thermo-sensitive genic male sterile rice accelerates hybrid rice breeding using the CRISPR/Cas9-mediated TMS5 editing system. Sci Rep 6, 37395 (2016).

31. Zhao, F. J., Ma, Y., Zhu, Y. G., Tang, Z. \& McGrath, S. P. Soil contamination in China: current status and mitigation strategies. Environ Sci Technol 49, 750-759 (2015). 
32. Sun, L. et al. Genetic diversity, rather than cultivar type, determines relative grain Cd accumulation in hybrid rice. Front Plant Sci 7 , 1407 (2016).

33. Feng, Z. et al. Efficient genome editing in plants using a CRISPR/Cas system. Cell Res 23, 1229 (2013).

34. Hyun, Y. et al. Site-directed mutagenesis in Arabidopsis thaliana using dividing tissue-targeted RGEN of the CRISPR/Cas system to generate heritable null alleles. Planta 241, 271 (2015).

35. Li, T., Liu, B., Spalding, M. H., Weeks, D. P. \& Yang, B. High-efficiency TALEN-based gene editing produces disease-resistant rice. Nat Biotechnol 30, 390-392 (2012).

36. Nekrasov, V., Staskawicz, B. \& Weigel, D. Targeted mutagenesis in the model plant Nicotiana benthamiana using Cas9 RNA-guided endonuclease. Nat Biotechnol 31, 691-693 (2013).

37. Svitashev, S. et al. Targeted mutagenesis, precise gene editing, and site-specific gene insertion in maize using Cas 9 and guide RNA. Plant physiol 169, 931 (2015).

38. Townsend, J. A. et al. High-frequency modification of plant genes using engineered zinc-finger nucleases. Nature 459, 442-445 (2009).

39. Shan, Q. et al. Targeted genome modification of crop plants using a CRISPR-Cas system. Nat Biotechnol 31, 686 (2013).

40. Xu, R. et al. Rapid improvement of grain weight via highly efficient CRISPR/Cas9-mediated multiplex genome editing in rice. $J$ Genet Genomics 43, 529-532 (2016).

41. Li, M. et al. Reassessment of the four yield-related genes Gn1a, DEP1, GS3, and IPA1 in rice using a CRISPR/Cas9 System. Front Plant Sci 7, 377 (2016).

42. Wang, F. et al. Enhanced rice blast resistance by CRISPR/Cas9-targeted mutagenesis of the ERF transcription factor gene OsERF922. PloS One 11, e0154027 (2016).

43. Sun, Y. et al. Engineering herbicide-resistant rice plants through CRISPR/Cas9-mediated homologous recombination of acetolactate synthase. Mol Plant 9, 628-631 (2016).

44. Huang, S., Weigel, D., Beachy, R. N. \& Li, J. A proposed regulatory framework for genome-edited crops. Nat Genet 48, 109-111 (2016).

45. Ma, X. et al. A robust CRISPR/Cas9 system for convenient, high-efficiency multiplex genome editing in monocot and dicot plants. Mol Plant 8, 1274-1284 (2015).

46. Endo, M. Multigene knockout utilizing off-target mutations of the CRISPR/Cas9 system in rice. Plant \& cell physiology 56, 41-47 (2014).

47. Puchta, H. Applying CRISPR/Cas for genome engineering in plants: the best is yet to come. Curr Opin Plant Biol 36, 1-8 (2016).

48. Sasaki, A., Yamaji, N., Xia, J. \& Ma, J. F. OsYSL6 is involved in the detoxification of excess manganese in rice. Plant physiol 157, 1832-1840 (2011).

49. Yang, M. et al. OsNRAMP5 contributes to manganese translocation and distribution in rice shoots. J Exp Bot 65, 4849-4861 (2014).

50. Marschner, P. Marschner's Mineral Nutrition of Higher Plants, 3rd ed. (2013).

51. Xu, X. Y., Mcgrath, S. P., Meharg, A. A. \& Zhao, F. J. Growing rice aerobically markedly decreases arsenic accumulation. Environ Sci Technol 42, 5574-5579 (2008).

52. Ishimaru, Y. et al. Characterizing the role of rice NRAMP5 in manganese, iron and cadmium transport. Sci Rep 2, 286 (2012).

53. Takahashi, R. et al. From laboratory to field: OsNRAMP5-knockdown rice is a promising candidate for Cd phytoremediation in paddy fields. PloS One 9, e98816 (2014).

54 Pyott, D. E., Sheehan, E. \& Molnar, A. Engineering of CRISPR/Cas9-mediated potyvirus resistance in transgene-free Arabidopsis plants. Mol Plant Pathol 17, 1276-1288 (2016).

55 Rowland, L. J. \& Nguyen, B. Use of polyethylene glycol for purification of DNA from leaf tissue of woody plants. Biotechniques 14, 734 (1993).

56 Larkin, M. A. et al. Clustal W and Clustal X version 2.0. Bioinformatics 23, 2947-2948 (2007).

57 Yoshida, S., Forno, D. A., Cock, J. H. \& Gomez, K. A. Laboratory manual for physiological studies of rice, 3rd ed. (1976).

\section{Acknowledgements}

We thank Prof. Yao-Guang Liu (South China Agricultural University, Guangzhou) for kindly providing the plant binary vector pYLCRISPR/Cas9Pubi-H and the pYLgRNA plasmids. This work was supported by the Major Scientific Research Project of Hunan Province (Grant No. XCNZ [2014] 180), Hunan Provincial Natural Science Fund for Distinguished Young Scholars (Grant No.11JJ1007), the Natural Science Foundation of Hunan Province (Grant No. 14JJ7084) and the Earmarked Fund for Modern Agro-Industry Technology System of China (Grant No. CARS-01-04B).

\section{Author Contributions}

H.L., S.X., and B.Z. designed the study. L.T., B.M., Y.L., Q.L., L.Z., H.H., W.W., X.Z., Y.S., Y.P., Y.H., and Y.P. performed the experiments. L.T. prepared the figures and tables, and wrote the manuscript. C.C., X.F., H.L., S.X., and B.Z. discussed the results, supervised and edited the paper. All authors reviewed the manuscript.

\section{Additional Information}

Supplementary information accompanies this paper at https://doi.org/10.1038/s41598-017-14832-9.

Competing Interests: The authors declare that they have no competing interests.

Publisher's note: Springer Nature remains neutral with regard to jurisdictional claims in published maps and institutional affiliations.

(c) (i) Open Access This article is licensed under a Creative Commons Attribution 4.0 International

License, which permits use, sharing, adaptation, distribution and reproduction in any medium or format, as long as you give appropriate credit to the original author(s) and the source, provide a link to the Creative Commons license, and indicate if changes were made. The images or other third party material in this article are included in the article's Creative Commons license, unless indicated otherwise in a credit line to the material. If material is not included in the article's Creative Commons license and your intended use is not permitted by statutory regulation or exceeds the permitted use, you will need to obtain permission directly from the copyright holder. To view a copy of this license, visit http://creativecommons.org/licenses/by/4.0/.

(c) The Author(s) 2017 